\title{
“Design for Enterprises": Developing European SMEs Capabilities for Design-driven Innovation
}

\author{
Marinella Ferrara \\ Politecnico di Milano, Italy \\ Chiara Lecce \\ Politecnico di Milano, Italy
}

Follow this and additional works at: https://digitalcommons.uri.edu/mgdr

Part of the Entrepreneurial and Small Business Operations Commons, Industrial and Product Design Commons, Organizational Behavior and Theory Commons, Other Teacher Education and Professional Development Commons, and the Technology and Innovation Commons

\section{Recommended Citation}

Ferrara, Marinella and Lecce, Chiara (2019) "'"Design for Enterprises": Developing European SMEs Capabilities for Design-driven Innovation," Markets, Globalization \& Development Review. Vol. 4: No. 2, Article 7.

DOI: 10.23860/MGDR-2019-04-02-07

Available at: https://digitalcommons.uri.edu/mgdr/vol4/iss2/7

This Article is brought to you for free and open access by DigitalCommons@URI. It has been accepted for inclusion in Markets, Globalization \& Development Review by an authorized editor of DigitalCommons@URI. For more information, please contact digitalcommons-group@uri.edu. 


\section{"Design for Enterprises": Developing European SMEs Capabilities for Design-}

driven Innovation

\section{Cover Page Footnote}

We acknowledge all ADI collaborators of DfE activities, in particular Dario Moretti, Daniela Martino, Susanna Vallebona Andrea Rovatti, and Simona Finessi for supporting. We also acknowledge the partners RINA (Andrea Pestarino and Maddalena Garrone), MIP, and the colleagues Francesco Zurlo and Arianna Vignati for their fundamental contribution. 


\section{Markets, Globalization \& Development Review}
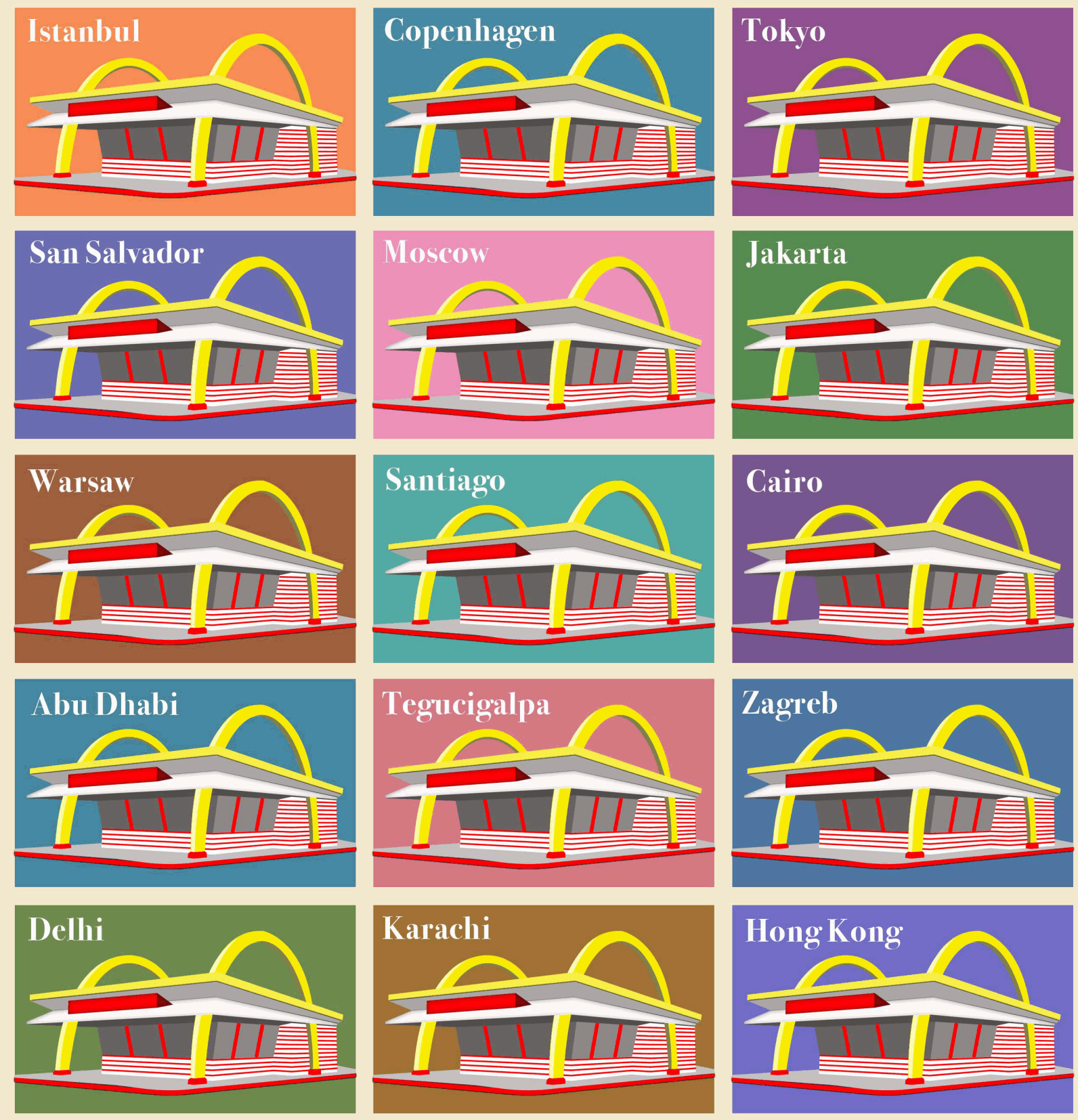

This article is available in Markets, Globalization \& Development Review: https://digitalcommons.uri.edu/mgdr/vol4/ 


\section{"Design for Enterprises": Developing European SMEs Capabilities for Design-driven Innovation}

\section{Introduction}

Since decades, the international scientific communities have been acknowledging the central role of design thinking as a driver of innovation. The importance of design as a strategic source of problem solving, problem finding and value creation has been argued by design organizations, like the Bureau of European Design Associations (BEDA) (Macdonald 2004), scholars (Buchanan 1992; Brown 2009; Martin 2009; Lockwood 2010; Teal 2010; Cross 2011) and practitioners, and increasingly investigated to recognize the competitive advantages within the management field (Capaldo 2007; Dell'Era and Verganti 2007). Today design thinking is conceived as a way of thinking that leads to transformation, evolution, innovation, new ways of living, and new ways of managing business. Design thinking is not just an engine for innovation promoted by designers, but also to multidisciplinary teams in every type of organization. It offers new models and tools that help to improve, accelerate and visualize every creative process making it accessible not only to designers.

In 2009, Tim Brown's book Change by Design. How Design Thinking Transforms Organizations and Inspires Innovation, addressed managers on every level of business, by saying "You don't have to be a designer to benefit from using design thinking", and he added: "contemporary innovation should focus on designing the user's emotional experience" (Brown 2009). Starting from this assumption, design thinking has been considered as a method for creative problem solving, with the intent to foster innovation (Brown 2009, Martin 2009, Liedtka 2015).

In the same year, Roberto Verganti's book Design-driven Innovation. Changing the Rules of Competition by Radically Innovating What Things Mean (2009), that first introduced this naming (design-driven innovation) in the field of management, describes the design process that has characterized some of the most interesting innovations in the world panorama in the past years, starting from Italian small and medium enterprises. Verganti identified the fundamentals of the design approach. It is not limited to the aesthetics of forms or functions, and not strongly based on technological innovation, but starts from the meaning of innovation for consumers, proposing a new vision on the user's experience with products and services. 
Unlike Tim Brown, who states "design thinking depends upon observing how people actually use products" (Brown 2009), Verganti's theory asserts that the radical innovation research process by creative people or organizations, as well as designers and managers, is based on the why of a new product or service. He suggests that companies build relationships with "interpreters" (individuals and organizations) capable to translate in projects people needs and desires. They help identifying the "meaning" of the proposed innovation for users and customers. These latter are at the center of the design research process, as well as the design culture and sensibility, with its ability to give new meaning to things, able to satisfy latent needs and open new markets, creating breakout products radically distant from the past and able to show a new future (Verganti and Dell'Era 2014).

Asking the why of a new product or service, design innovators add "unsolicited meaning" that consumers don't even know they're craving, and they create products people love (and buy) because they are so different from other products that dominate the market. The why identifies the reason things are used (job to be done, functionality and performance), as well as a complex set of qualities depending on the experience they propose, and the baggage of symbols and emotions that they carry with them and that determines the meaning that each one attributes to them (language, reasons for a choice, social messages, etc.)

According to Tim Brown and Roberto Verganti, one from the USA and the other from Italy, managers have to improve their capabilities on design thinking for their business, because this gives competitive advantages.

Observing large organizations, that operate globally, not included in the generally-accepted category of design oriented, like IBM and GE, applying the principles of design to the way people work, Jon Kolko (2015) stated that "design thinking is an essential tool for simplifying and humanizing [...]". The shift towards design thinking is not easy, but it helps to make complex systems simple, intuitive, and pleasurable. It increases the capability of accepting ambiguity, embracing risk, and resetting expectations. For this reason, design thinking is a core competence to develop a responsive and flexible organizational culture (Kolko 2015).

The fact that design can improve the firm performance appears nowadays unquestionable. Design thinking is making the headlines, with an extremely rapid diffusion in the practice and interest of organizations at every level of business.

On the ground of these perspective changings, during the last decade, the European Commission has strongly invested in design- 
driven innovation approach, i.e. the approach to innovation lead by design, aiming "to accelerate the take-up of design in industrial" and also in innovation policies at European, national, and regional level because "Design creates value and contributes to competitiveness, prosperity, and well-being in Europe." (EU 2013)

The approach to innovation powered by design shall become new leverage for European industry, linked to territorial competences, in particular for Small and Medium Enterprises (SMEs) that represent 99\% of all businesses in the Europe (EU 2015). They are the engine of the European economy, despite their fragility, due to reduced resources, and problems they have often to deal to (market failures, structural barriers, difficulty in turn-over).

Design-driven innovation is a big opportunities to strengthen the position of SMEs products in the market through several strategic actions, including: adding products value, open new niches into the market, to rich better satisfaction of users and development of customer loyalty (user-centered design approach), efficiency of the production system and of their value chain, higher organizational performance of the company leveraging on the lean approach (LCC design), increased vision of the future market changes (global challenges and megatrends).

The EU Action Plan for Design-Driven Innovation (Design for innovation 2013) aimed to accelerate the take-up of design and to create the capacity and competencies needed to implement the innovation policies. It promoted:

- understanding of design impact on innovation

- design-driven innovation in the industry to strengthen competitiveness

- design as a means for renewal in the public sector

The Action Plan, built on the report "Design for Growth and Prosperity" produced by the European Leadership Board Report in 2012, included the program of a "Design for Enterprises" project, a set of courses to support design-driven innovation approach in Small and Medium Enterprises (SMEs) all around European areas.

In 2015, the Executive Agency for Small and Medium-sized Enterprises (EASME) ${ }^{1}$ launched the call for tenders "Capabilities for

\footnotetext{
1 In 2013, EASME has been set-up by the European Commission to manage on its behalf several EU programs for SMEs. It ensures that actions funded by these programs deliver results and provide the Commission with valuable input for its policy tasks.
} 
Design-Driven Innovation in European SMEs" funded by $\mathrm{H}_{2020^{2}}$. Responding to this call, the consortium composed by D'Appolonia ${ }^{3}$, MIP/Politecnico di Milano ${ }^{4}$ and ADIper ${ }^{5}$, proposed the project Design for Enterprises (DfE), a training program based on the convergence of design thinking competencies developed by the three partners among different disciplines, areas of design and technological application.

The aim of the project was to spread the design-driven approach across the European Member States and Associated Countries SMEs, putting special emphasis on addressing countries and regions not yet advanced in applying design-driven innovation. The target of the project comprehended European SMEs that were interested in improving their design management skills to constantly invest in product, process, service or business model innovation, as well as organizations, business intermediaries, local public entities working daily in direct interface with SMEs supporting the innovation process (such as innovation agencies, incubators, and Enterprise Europe Network).

According to the project proposal, the training courses aimed to increase design competences through a complementary set of skills within a global vision, but also respecting the valorization of local EU Countries' peculiarities.

From April 2016 to July 2018 a total of 54 courses in 30 countries (among the European Member States and Associated Countries to H2020) have been delivered, including 20 full courses and 34 short courses. Conforming to the DfE final report (2018) more than 1000 people from SMEs and business intermediaries have been trained from April 2016 up to July 2018 (Garrone, Morelli and Pestarino 2018). The training sessions

\footnotetext{
2 Horizon 2020 is the biggest EU Research and Innovation program providing $€ 80$ billion of funding available over 7 years (2014 to 2020) and promoting innovation breakthroughs and discoveries from the lab to the market (https://ec.europa.eu/programmes/horizon2020/what-horizon-2020).

${ }^{3}$ D'Appolonia S.p.A, today RINA Consulting, is part of the RINA Group, the largest fully independent Italian engineering firm which provides integrated services to clients all over the world, both in the public and the private sector, in many industrial sectors.

${ }^{4}$ MIP is a non-for-profit consortium between the Politecnico di Milano (state university) and Italian leading public institutions and private industrial groups, based on the competencies of the Graduate School of Business. MIP has access to the deep knowledge provided by the Schools and the Departments of Politecnico di Milano, from the School of Management, to the School of Design.

${ }^{5} \mathrm{ADIper}$ srl is the company in charge of the service management for ADI Associazione per il Disegno Industriale, the Italian association that since 1956 brings together designers, enterprises, schools, design historians and journalists, to focus on the topics of design: designing, producing, communicating, distributing, training.
} 
have been officially delivered in English, French, German, Italian, Polish, Spanish and a selection of the training material has been also translated into the all hosting Countries' official languages.

The following paragraphs describe the general structure of the course with a special focus on the role of ADI, to be here considered as an explicative example of a design thinking approach applied to a business oriented training course. The final part of the paper is then dedicated to sum up the DfE first results and general considerations, in order to fix the positive and critical points occurred during the course.

\section{DfE Training Courses Structure: Contents and Phases}

The courses addressed issues that cover all the typical business processes: from strategic and market decisions, to production efficiency; from product and service design to material selection and analysis of the life cycle. The focus was to understand the new technologies, the cultural trends of the business, but, above all, the methods and the tools of design to put customers and users at the center of the company mission, listening, observing and interpreting their needs with creativity.

The main structure of the courses was based on two main levels of training: frontal and on-distance lessons and activities. Then, trainers could choose to follow two type of courses: the "Design-Driven Innovation Shortcourse", or the "Design-Driven Innovation Full Program".

The Short-courses Program aimed to introduce the basic concepts of design-driven innovation, to create a common vocabulary and to explain how design-driven innovation can be proposed as a service to SMEs. For this reason, during the short program, four strategic modules were presented: Introduction to Design-Driven Innovation, Creating Value by Innovation of Meanings, Megatrends and design, for changing business models and Guidelines to promote design-related services to SMEs, interspersed with team activities in order to consolidate theoretical concepts. After the event, if interested, the participants were able to go on the DfE platform and download any modules of the full program course, available on-distance.

The Full Program was composed by four mandatory phases: a faceto-face kick-off event, a number of on-distance activities, a Project Work and a face-to-face final event (Figure 1). 


\section{Figure 1. The "Design-Driven Innovation Full Program" four phases}

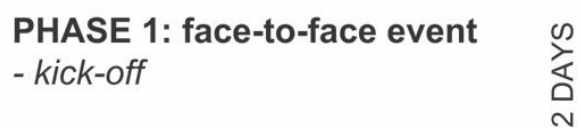

PHASE 2: on-line

- 3 mandatory modules

- 3+ elective modules

PHASE 3: on-line

- project work title definition

- project work draft

- project work finalization

PHASE 4: one-on-one

web conference

- projet work presentation

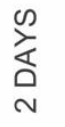

$\underset{n}{\stackrel{n}{I}}$

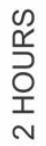

Source: Author's scheme

\section{Phase 1}

The face-to-face kick-off event (2 days) was based on a Master Class (or lecture) approach (properly leveled to a practitioner level), aimed to present the course program, giving to the participants the fundamentals on designdriven approach and evidencing design thinking potentialities among industry innovation strategy. Theoretical principles, as well as real examples of business cases, have been used during the front training in order to create an interactive and business-oriented session.

Case studies (selected to be understood all over Europe, by every type of participant and his/her knowledge of design) were particularly useful for the comprehension of the theoretical contents. For example, to facilitate the understanding of the module of "Design-Driven Innovation", one case study presented has been the Nintendo Wii (2006), which was able to lift the Nintendo company after a dark period, result of the hegemony of Sony Play station and Microsoft Xbox. The design-driven innovation was principally based on a switch of meanings: from game consoles as passive immersion in a virtual world for young adepts with a competitive approach to game consoles as active physical entertainment for everyone and just for fun. 
Another relevant case showed has been the Philips Ambient Experience (2004), a design-based transformation from System Design to Experience Design. The project started for a pediatric hospital in which the children were subjected to treatments in environments dominated by machinery and technology, environments, which caused anxiety in the children and their families. To reduce this anxiety Philips Design Research team (coordinated by designer Stefano Marzano) involved medical staff representatives, patients and their families, architects and designers. The elements involved in the new experience within the hospital included the use of projections, the invention of hypnotic stories and the creation of educational messages in order to distract and calm the children, so as to reduce examination times and treat more patients (Figure 2).

Figure 2. Slide of the Philips Ambient Experience project presented for the Design-Driven-Innovation Module during the kick-off events

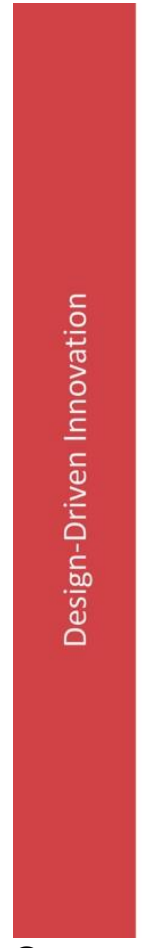

\section{Philips Ambient Experience (2004)}
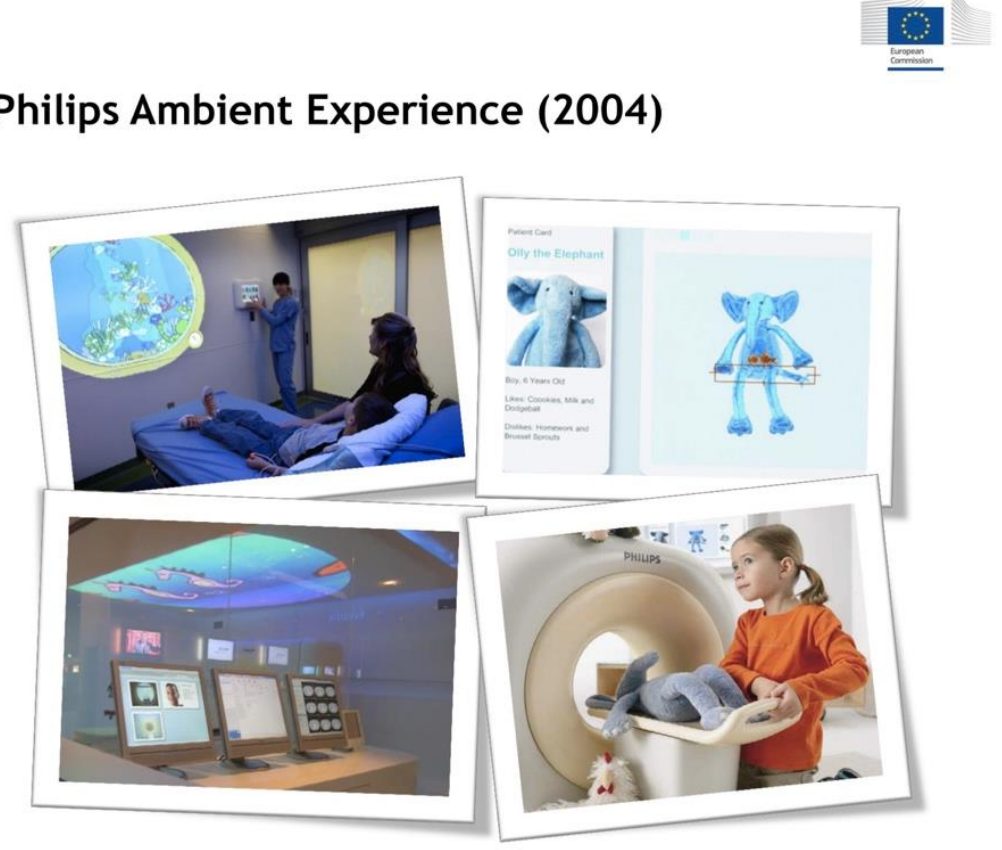

Source: DfE module "Design-Drive-Innovation"

In addition to the Master Classes, teamwork activities (as serious games) were specially designed (Figures $3,4,5$ ) in order to fix the contents from the lectures, to enhance participants' engagement and interaction and to facilitate networking opportunities. 
At the end of the kick-off event a dedicated team of ADIper presented a specific design-driven-innovation success story selected among ADI's numerous members, to exceed participants' expectations from the courses.

Figure 3. Photo during a DfE short course at ADI quarter, Milan, Italy 2016

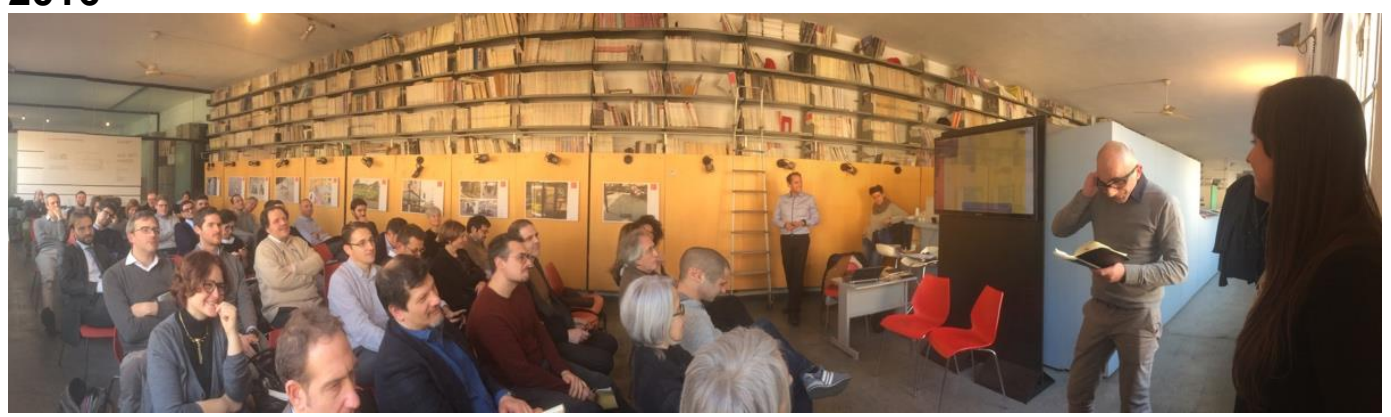

Source: Authors' picture

Figure 4 and 5. Photo of a DfE full program kick-off in Sofia, Hungary 2017
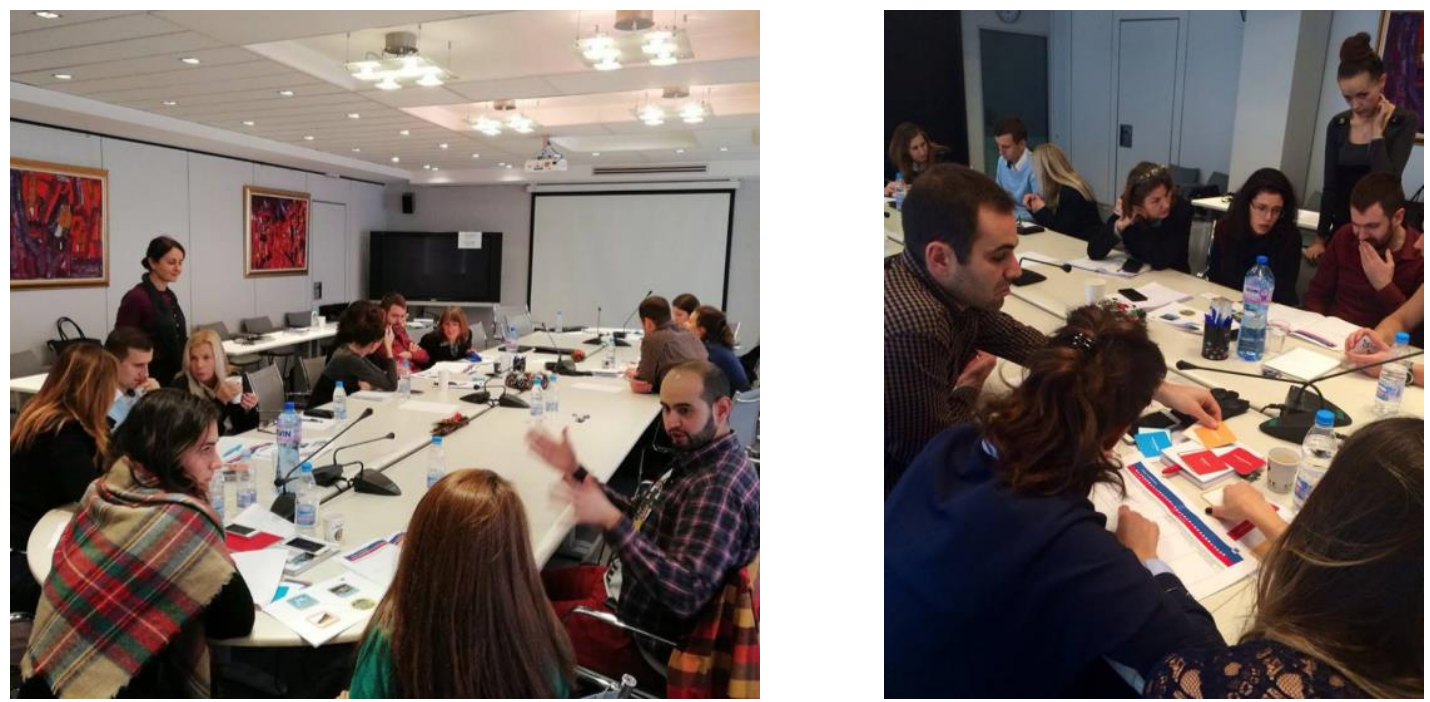

Source: DfE pictures 


\section{Phase 2}

The on-distance activities phase expected participants to choose at least six modules among the 15 available on a dedicated web platform, according to their specific objectives, fields of work and experience. Modules were divided into five different design areas:

1. Design - Tool of management: Global Future Trends and Business Models, Product \& Service- Its design and development, Design for problem solving, Communicating Innovation Through Metaphors;

2. Added Value Design to your product \& service: Design for Opening New Markets, Design for Shaping Products, Design for Future Products and Services, Design of Innovative Services;

3. Materials and technologies: Additive Manufacturing for Design, Design for Materials;

4. Effective product development: Lean design I and II (My waste game), Tools for Product Lifecycle Management I and II (game);

5. Design for sustainable products \& Services: Design for Life Cycle Assessment I and II (game), Design for Life Cycle Costing.

Each module was introduced by webinars, consisting of short videos and presenting a preview of the contents, in order to facilitate participants' choice, based on their specific interests. Than, a specific e-learning lesson was available for the didactical contents (about 30-40 slides) of the modules; in the e-learning platform, at the end of each e-learning there was a test for evaluating the performance of the participants.

Phase 3

Once most of the skills were acquired, each participant has been asked to develop and present a final Project Work, reflecting the typical field of action of his/her organization. The participants had to select one of their (potential) future customers and build on it a case study.

\section{Courses Achievements: Results and Participants' Feedbacks}

Among the total number of 54 courses supplied during the three years of the project, the average number of participants was set between 12 and 18 per course. (Garrone, Morelli and Pestarino 2018) In most cases (more than $80 \%$ of the courses) this target was respected or even overtaken (e.g. in Iceland, Bulgaria, Italy where the average number of participants was between 25 and 30). At the same time in some courses (full in Spain, short in Czech Rep., short in France, and short in Belgium), there was limited support from local the Enterprise Europe Network (EEN) partners and for this reason, the number of registered participants was lower than expected. 
Overall, during the three years of the project, 54 courses were organized in $30 \mathrm{EU}$ member states and associated countries. More than a thousand people, including SMEs and others, have been involved in the courses, exceeding the objectives initially envisaged by the European Commission (Pestarino 2018). A total of 418 people from SMEs and 584 people from business intermediaries' associations took part to the courses, respectively representing $42 \%$ and $58 \%$ of the total number of participants. (Garrone, Morelli, and Pestarino 2018) Furthermore, participants could be classified into three different categories on the basis of their knowledge on Design Driven Innovation: Basic (circa $50 \%$ of total participants); Intermediate (circa $43 \%$ of total participants); Advanced (circa $7 \%$ of total participants).

At the end of each course, participants were asked to answer a Satisfaction Survey and then also a Follow-up Survey was sent to all participants of both short and full courses about three months after the course date. These surveys have been a precious tool to measure participants interest of the courses, which was generally considered very useful with a constant high level of satisfaction. Only the courses organized in countries were the level of innovation is already very high (such as Denmark, Sweden, Finland), some participants reported that the material could be improved with more recent case studies. In fact, the level of satisfaction reflected the level of innovation performance of the countries. Meanwhile, the courses were very well received in countries such as Bulgaria, Hungary, Moldova, Turkey, Latvia, and Portugal, considered "Modest" or "Moderate" Innovator countries (Garrone, Morelli, and Pestarino 2018).

\section{Course Surveys}

The two different formats of training courses have been highly appreciated by the audience. Intermediaries especially liked the format of the short course, as it seems to be easier to replicate. In fact, the intermediaries that have actually proposed a training course to their associates and customers have mostly selected the short format. On the other hand, SMEs showed large interest in the full course, where they had the immediate opportunity of deepening certain themes and subjects.

Then, according to Inception Report, a follow-up survey was sent to the participants of both short and full courses about three months after the course date. It is useful to report some of the questions and answers to the follow-up survey. For example, one question was referred to the chance to put in practice what participants learned at the training course. The $64 \%$ answered yes, also reporting how design was implemented in their activity, 
like: including customer-centered approach in their company, focusing on new trends, adopting new strategies to understand customers and users' needs, improving their products and services communication (increasing their business), some others revised a business plan for their business and developed new products and/or services.

Another question concerned ideas participants wanted to implement after the training course that for some reasons at the end they were not able to carry out $(61 \%$ yes, $39 \%$ no). Some of the problems were: lack of budget/financial support discouraged the team to continue with the project; it was not possible to find partners with good knowledge; the tools provided are not always applicable to all situations; the decision maker didn't accept their proposal.

Participants' suggestion oriented to improve the DfE training course included the request of more: "how-to-do" design examples (place, time, financial resources, legal barriers, etc.), information about funding opportunities, negative examples, customized courses (on the basis of participants' background), materials like books and articles, local case studies.

\section{Changes during the Project Activities}

In 2017 a change in the format of the full course was proposed by the Consortium, accepted by the EU Commission and implemented. Initially, the full course was structured with an initial face-to-face event of two days, plus a final face-to-face event at the end of a period of three months, during which participants could learn from the online modules and prepare a final work. The final day was mainly organized to give participants the chance to present the project work. In most cases, this was not possible: sometimes because of confidentiality issues, sometimes participants had different priorities for the scheduled final day. In this direction, the Consortium proposed to replace the final day with a bilateral meeting (trainers + participants), held online, to provide the flexibility requested by most participants.

\section{The Role of ADI in Design for Enterprises}

Design outlooks connected to enterprises role, marketing, and commerce, are essential to enable SMEs to achieve new markets. ADI has always worked with the keywords of design production chain complexity, connecting enterprises, designers, distributors, experts on media for design and long life professional trainers, earning an international reputation. In this direction, the role of ADI has been primary in the communication task, also for its qualification within the European context and thanks to the connection with all main European design associations, like ICSID (International 
Council of Societies of Industrial Design), BEDA and ICOGRADA (International Council of Graphic Design Associations) of which ADI is member.

ADlper general Communication plan comprehended:

- the visual communication design and contents of project web pages www.designforenterprises.eu, on EASME website, and on all others Design for Europe platforms suggested;

- continuous promotion of project results and communication of the events through all the social platforms, in order to maintain all the people involved updated and to attract all the intermediate organizations to the relevant web pages;

- creating and sending newsletters once a month to the dynamic and continuously updating data-list;

- promotional information material divulgation (leaflet, brochures, etc.) during the main strategic events;

- the production of a video dedicated to a successful case study selected from ADl's members.

- to collaborate actively during the teamwork activities of the Full Program face-to-face events ("play 40!" cards serious game).

\section{Communication Task}

The purpose was to reach and involve European SMEs decision makers and influencers (main target), a large number of other organizations gravitating around SMEs, managers and industrial stakeholders. A target which primarily asks for: new and original points of view on increased problems that entries to their professional culture, guaranteeing an efficient activity within EU enterprises; availability of instruments easily applicable to the specific situation of each Country and to the specific business, declinable with an immediate efficacy into everyday problems.

Broadly the main communication message was "Change your point of view!", referring to the importance of a revolution brought by a design thinking approach within a company that has never effectively (or deliberately) adopted it.

A dedicated ADl's team was in charge of the communication tasks and professional graphic designers Susanna Vallebona and Andrea Rovatti designed the visual identity of the project (according to the EU visual identity line and related visual artifacts like the logo, presentation, and newsletter layout, poster and brochure, website, DEM and etc.) (Figure 6). Their concept was characterized by several colored round graphic elements that symbolized the many countries and cultures around Europe, as well as their interchanging realities. The visual communication design was also 
characterized by: attentive research of meaningful images adapted to the target; a constant work on the contents concerning the project activities to be visualized in the newsletter through the website.

Figure 6. Visualization of a DEM of Design for enterprises on the I-pad screen.

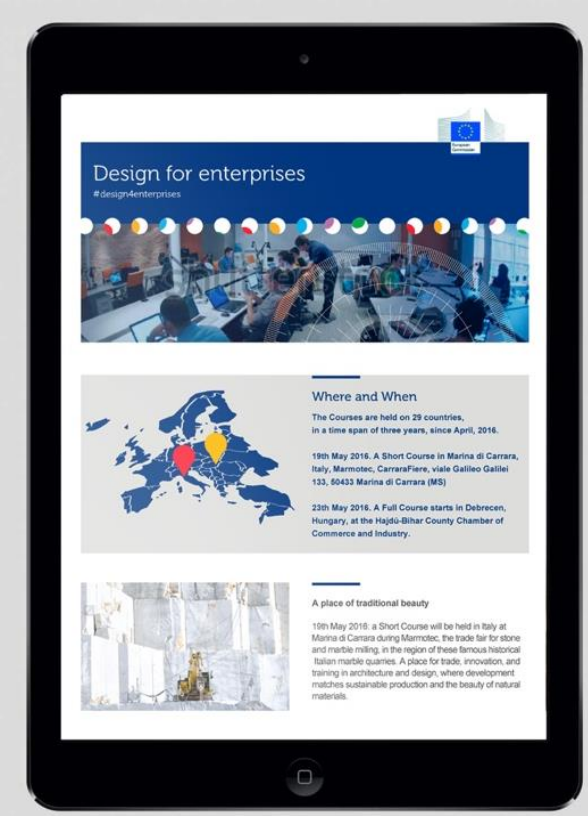

Source: S. Vallebona and A. Rovatti project of DfE Visual Identity

Considering the geographical extension of the project, the target, and the objectives for the promotion and widest diffusion of the project activities, it was considered to reach a large audience avoiding the use of traditional media and marketing tools (advertising campaigns, TV communication, billposting). The main media for communication was Social networking on the internet, linked to DfE web platforms.

Being the engagement mostly dedicated to industrial stakeholders, Linkedln has been considered the main social media platform. A Designdriven Linkedln group have been created to trigger and stimulate the discussion among the subscribed members. Also, Facebook, Twitter, and Periscope has been used to enlarge the community of followers. Continuous promotion of the project and events through Social Web platforms kept all the stakeholders updated, arousing fidelity to the relevant 
web pages. Social Media Community increased slowly, but it was "real" and responsive.

The web platform has been developed by D'Appolonia, comprising a public (for news and basic information about the program and the courses) and a private area to access at the courses and their modules (webinar session + e-learning). Besides the training program information, the web platform was the medium dedicated to the news, with a section of public events and communication contents constantly updated.

Social networks revealed to be more useful to build an online community, where people could continue to be engaged in the project and from which the Consortium could extract success stories or case studies. Future communication plans should probably consider the two different purposes and define an optimized strategy both for recruitment and community building, since the beginning.

At the end of the project, the number of contacts reached a total of 359.711 , thereby increasing the number of contacts presented in 2016 by $156 \%$ (Garrone, Morelli, Pestarino, 2018, p.75). According to the Final Report, all targets of communication were reached and overcome, also thanks to the local EEN members (Garrone, Morelli, Pestarino, 2018, p.103).

Other communication activities were implemented during the courses by an ADl's specialized team (linked to Design Department of the Politecnico di Milano) in order to engage the audience with interesting contents during the opening of the long program courses, with the production of video contributes, specific events posters and flyers.

\section{The Loccioni Group Evolution through Design-driven- \\ Innovation}

Beyond the primary role pertaining to the communication task, ADlper contribution to the general project concerned also providing interesting application of the design-driven innovation to be presented during the faceto-face events and selected from its numerous members.

In particular, ADIper produced a video dedicated to the story of the Loccioni Group, using company's archive materials, as well as original interviews with its managers, and designer, focusing on the design strategies and main steps that have enabled Loccioni to win the competitive challenges, to grow from a small to large size enterprises, and achieve international success (Figure 7). ADlper chose the Loccioni case study because it didn't focus on the common way people think of design that is primarily associated with products aesthetics, shape and fashion. Loccioni develops technological implementation services for other companies and 
does not manufacture finished product for individual consumption. Therefore, this case study gave the emblematic message that also B2B (Business to Business) oriented enterprises need to implement design thinking to succeed in the market. Learning about Loccioni's design approach was considered an excellent starting point for those who wish to improve their own organization. The Japanese designer Isao Hosoe, who contributed to the Loccioni enterprise turns, said that this company is a basic model to export and spread all over the world (Hosoe 2008).

This example talks about how an enterprise is able to find new opportunities and open up new markets, how it's able to manage the innovation processes with creativity, how it's able to optimize, improve and add value to its work as well as to the work of its customers, and so it's able to succeed despite the past and current economic crisis, that has impacted many other companies.

\section{Figure 7. Frames from the Loccioni's Video presented by ADI during} the face-to-face events
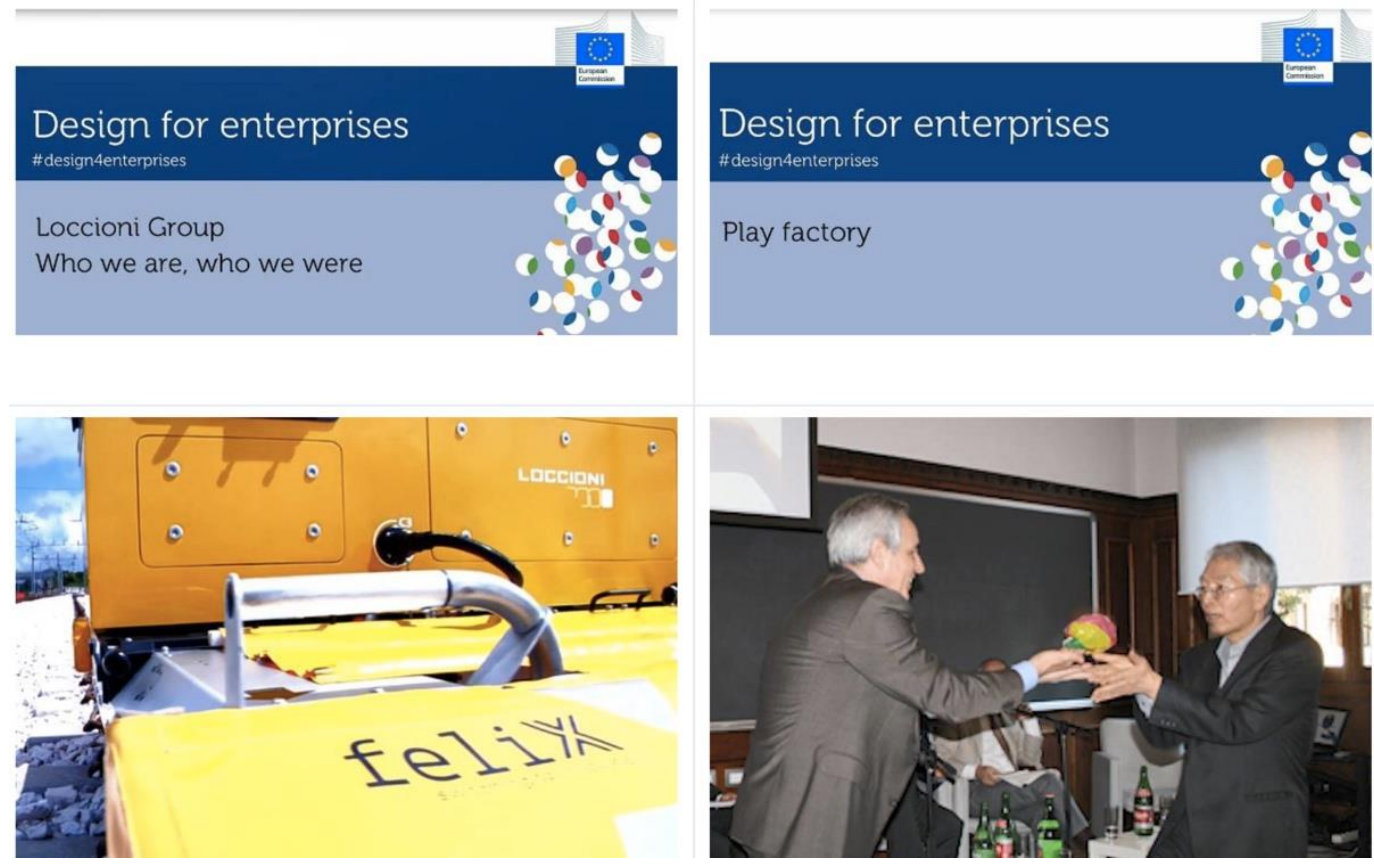

Source: Authors' picture.

In the Loccioni' story the collaboration with Merloni household appliances company in order to test their production line, and solve their several problems, was the start of small company evolution. In that moment 
they understood that there was a new need in the industrial sector and so a new space to succeed, practically actuating a Blue Ocean Strategy (Chan Kim and Mauborgne, 2005). They took the challenge and organized a new process of working, switching from a low level of competence to a high level of competence. So it was important to integrate new people, especially young engineers, opening a relationship with universities.

Loccioni's turning point was to catch the opportunity of a new request of competences coming from big industries. It was more like understanding a need from one of their customers, because at those times the request was not clearly expressed. After the turning point, Loccioni's core business changed from producing electrical systems to developing projects for solving problems. The complexity of the work increased a lot, and also the responsibility of the entrepreneur. It was at this time that Loccioni must define a new mission and strategy. The mission was: to be a problem solver for other companies, their customers. So, the strategies were: flexibility, customization and continuous improvement on technology for the best quality. In order to assure the flexibility, the company learned how to be an open enterprise, a site for cross-pollination of know-how were different skills, people and ideas can integrate to achieve innovation. In order to assure the best quality for their customers, they must hear and learn from them and improve the knowledge about how means the best quality (Design for Enterprises, 2017a).

After this step, it was the time for approaching design culture. Maria Paola Palermi (the Communication Manager of Loccioni group) stated: "Design is a behavior; design is an approach".

Design is a different way of looking and thinking, compared to the engineering approach. Design switches the way of looking from the technical quantitative one to that of human perception of quality, relative to time and space. It's a matter of experiences, subjective and intersubjective dimension of people's comfort and pleasure. They learned the importance of Ergonomics and Proxemics. Ergonomics is the discipline that studies the relationship between the size of the human body and the measures of the products in order to optimize their use. Proxemics is the discipline that studies human gesture, the human spatial requirements and the effects that the distance or the population density has on behavior, communication and social interaction.

Thanks to the collaboration of the Japanese designer Isao Hosoe, with the passion of studying workplaces and their impact on working people, design was for Loccioni a cultural revolution. They learned that a design approach means not only design their machines (the measuring machines), 
but also consider their value as quality of life, and the first quality to design was their quality of life at work.

The most impacting message of Isao Hosoe was "design is like throwing a stone in a pond, the waves move from the center towards a hypothetical future and towards the person who threw it". It is to highlight the consequence of a project, the responsibility. But at the same time, he worked to promote and diffuse a new creative working culture, with "Play Factory". As suggested by Isao Hosoe, "to play is the only way to get the best creative performances". So the factory hosted many activities of training, communication, and interaction in the workplace by gaming; these activities were a new way to inspire quality of life with colleagues, and to preserving and regenerate the vital energy of the people in terms of creativity, innovation, and growth.

Therefore, design helped Loccioni "to turn data into value", because data they collect, measure and manage are not only useful to improve process efficiency for their customers, but also to increase the tangible and intangible values of products for final users: design makes them more comfortable, easy to use, safe, friendly, appealing, that is design the user experience of a product; and design the communication on the difference of the product in respect to the others, that is the message.

Isao Hosoe thought them that they should design not just the machine and the work-space but also its effects on their customers' productive processes and on the company itself "Not only the umbrella but also the shade". So they focused on transforming quantity, which was their expertise (the measurement), into perceived quality.

Isao Hosoe stated, "design is like throwing a stone in a pond, the waves move from the center towards a hypothetical future and towards the person who threw it". This is to highlight the consequence of a project, the responsibility and the effects on human life and environment. But at the same time, he worked to promote and diffuse a new creative working culture, with the slogan Play Factory. As suggested by Isao Hosoe - "to play is the only way to get the best creative performances". So the factory hosted many activities of training, communication, and interaction in the workplace by gaming; these activities were a new way to inspire quality of life with colleagues, and to preserve and regenerate the vital energy of the people in terms of creativity, innovation, growth (Design for Enterprises, 2017b).

Today Loccioni's business areas are five: Mobility, Energy, Environment, Industry, and Medicine.

In numerous cases, Loccioni's customers have been asking to equip their laboratories with the same structures of Loccion workplace. Customers, partners, and big groups visit Loccioni to "play" and use its 
creativity tools with Loccioni's people and the European Commission itself has defined these tools essential to develop creativity in Small and Medium Enterprises.

Analyzing the first year of the training project feedbacks, in order to be more efficient and strongly engaging the audience, the first version of the video has been cut and divided into only three parts, focusing more on the strategies that enabled Loccioni to achieve international success. This shorter and clearer version of the video was much more appreciated.

At the end of the project, two new short videos have been designed for the full program courses' finals events. The videos, narrated by Lorenzo De Bartolomeis, showed the relationship between Loccioni and Isao Hosoe and the designer's approach.

\section{"Play 40!" Groups' Activity}

As previously introduced, serious games were another successful activity performed during the face-to-face event in order to fix and stimulate the design thinking approach among the participants.

ADIper team was in charge of one of this activities experimenting the "Play40!" game, which consists of a deck of playing cards designed by Isao Hosoe in occasion of the Loccioni Company $40^{\text {th }}$ anniversary, imaging them as a useful tool to stimulate the design process among the company's employers.

Corresponding to Isao Hosoe's Play Factory philosophy, this deck of cards serves to exchange ideas trying to create innovative projects in an entertaining way fueling improvisation, spontaneity, and creativity. It is a perfect tool for brainstorming, as shown in the DfE video for kick-off events in Full program courses.

Complying with the curiosity and interest expressed by the participants in the events face-to-face knowing, starting from the second year of the DfE's training program, this game has been introduced, at the end of the Loccioni's video presentation, to the participants of the face-toface events correlated to the full courses. Participants were divided into heterogeneous groups of a variable number of 5-8. After a short explanation of the game by the ADI tutor, the groups had circa 30 minutes in total to play together, using only six drew cards and using them creatively focusing around a specific idea/startup project they had to choose at the beginning of the teamwork (they were invited to work on their real ideas of project).

6 "Play40!" is provided by Corraini publisher. For more information about: http://www.playfactory.it/?cat=14 
The basic concept of "Play 40" originates from a traditional Japanese game called karuta, based on the association between words and pictures, in fact, it is composed of 40 images and 40 words and concept. So, making association among the cards, the game is a tool for generating new ideas in the work team, as well as for brainstorming with customers and guests. Gaming they can understand what ideas count, how the one is linked to the other, which are more important for what is to be obtained. By playing with the different stakeholders of a project, it is possible to understand their needs and even more their unconscious desires and to find creative solutions. Basically "Play 40" game helps people (in particular nondesigners) to open their minds and to have a different prospective about the concepts they are developing, teaming with others (Figure 8).

\section{Figure 8. "Play 40" game activity during the face-to-face event in} Ljubljana (March 2017)

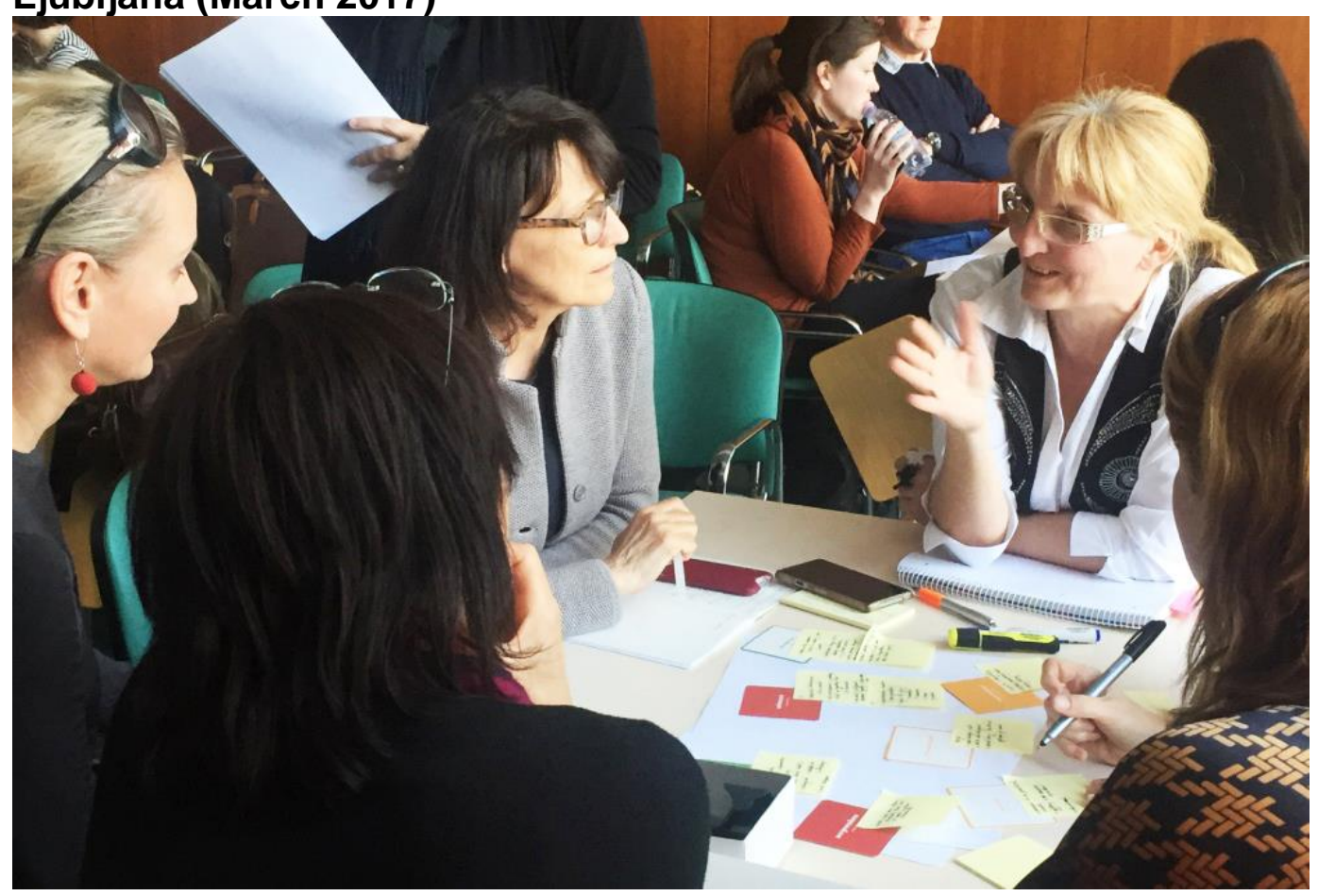

Source: Authors' picture.

\section{Final Considerations and Results}

The project covered almost all EU Member States and a large part of the Associated Countries (Figure 9), a much larger number of countries than 
the initial request ${ }^{7}$. The lessons learned in the geographic scope are then wide and consider all the different European design attitudes. The focus on the countries with a lower design-driven innovation system (in particular Eastern and Baltic countries) revealed to be a very good choice: in general, the participation from these countries has been higher than the average. Also in the Associated Countries the participation was generally high, driven also by the reason that involvement in EU project is less common and so it aroused interest and curiosity at the local level. Moreover, taking also into consideration the level of the training courses, it is evident that the higher added value for participants was reached right in these countries. The suggestion is to focus future efforts further there, to fill the remaining gaps with more innovator countries. Moreover, participants appreciated the translation into several languages: apart from the easiness of reading, it was perceived as important customization of the course (Garrone, Morelli, and Pestarino 2018).

\section{Figure 9. Geographical coverage of DfE}

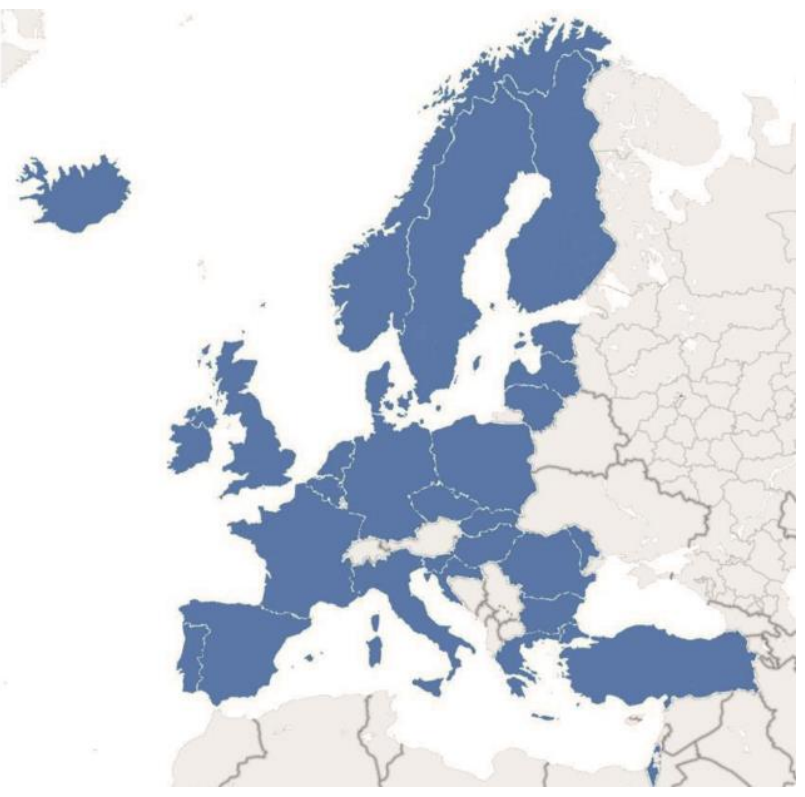

Source: (Garrone, Morelli, and Pestarino 2018).

${ }^{7}$ Belgium, Latvia, Bulgaria, Lithuania, Croatia, Malta, Czech Republic, Moldova, Denmark, Netherland, Estonia, Norway, Finland, Poland, France, Portugal, Germany, Romania, Greece, Slovak, Hungary, Slovenia, Iceland, Spain, Ireland, Sweden, Israel, Turkey, Italy, United Kingdom. 
As a direct result from the surveys, another suggestion concerns the two typologies of the training program (Full Course and the Short Course): in the future, the two options should be proposed again but, possibly, the communication should be targeted more on intermediaries for short events and on SMEs for the full ones, without mixing too much the two types of participants. This could also be useful to review the "train the trainer" overall schemes: short courses are in fact more suitable for intermediaries that being (almost) novel to the theme - could organize events for showing the basics of design thinking to their associates, maybe inviting some local success cases, as testimonials.

Full courses instead could be structured for a more internal future replication, where participants could provide to colleagues an initial overview of the tools of design and suggest more specific topics to the different departments.

Participants, being so close to business, mostly appreciated the predominance of case studies over the theory (Garrone, Morelli, and Pestarino 2018). However, a weakness the material showed in the last months of the project was directly caused by the speed of evolution of the world of design. In fact, after three years from the creation of the presentations, most of the used cases were already well known by some participants (especially those really involved and passionate of the topic) while, some others were already overcome by new ideas and further evolution steps. On one hand, this was useful to open a more interactive discussion with participants; on the other hand, a list of new case studies would be welcome to increase the curiosity of participants.

All these considerations have formed the base for the organization of a final event at the conclusion of the three years' program, with the title "Change your point of! Tools and experiences for SMEs development", held in Milan on July 2018. The event started with a co-creation workshop in collaboration with OIPEC (Open Innovation Platform for UniversityEnterprise Collaboration), co-funded by the Erasmus+ Programme of the European Union, to motivate companies to co-design training courses and to bring innovation. The workshop has been settled as a gamification session during which DfE participants were asked to tell their stories and to make a brief presentation of their project work, in order to give them an opportunity to disseminate and communicate their ideas (Garrone, Morelli, and Pestarino 2018).

\section{From Project Work to real Success Stories}

One of the main result of the entire project is ascribable to the many success stories directly originated from the DfE's Project Works. A selection of these 
stories has been reported in the final report (Garrone, Morelli, and Pestarino 2018), pointing out which kind of strategies and modules from the courses has been applied by SMEs to finalize their design-driven startups.

"Elektronio Handcrafted Vehicles", founded in Thessaloniki in May 2015, is an awarded Greek startup. It is a clean-tech mobility solutions company, which makes premium electric bicycles with a revolutionary design, introducing also an urban commuting tool with mini cargo capacity. The company focused on the module "Customer Centred Design" because the idea of the project was to upgrade the existing model, adding storage spaces, making it closed-all season. Then, they demonstrated to consider the "Global Future Trends" module emphasizing more the clean-tech brandsustainable mobility aspect and targeting the elderly population. The project has been oriented to different custom editions for B2C \& B2B customer, i.e. an extra cargo edition for companies, or an off-road edition for tourism industry applying fully the "Design Driven Innovation" module indications.

Another example is a services' provider SME, the agency "ENRIGA", which represents companies and brands in new markets helping them to expand and grow efficiently. The agency's services include market research and analysis, sales and marketing strategy and planning, partnership negotiations, coordination of daily operations, customer support. Everything so the client does not need to employ people in the territory from the first day especially without knowing the market. ENRIGA's mother country is Latvia, and it operates in Lithuania and Estonia from Riga having local representatives in Vilnius and Tallinn. The agency has either partner agencies, individuals - representatives, or its own people in the UK, Uzbekistan, Kuwait, Ukraine, and looking for new markets to enter (Garrone, Morelli, and Pestarino 2018).

"Mamas\&Papas" is a UK based SME which designs and commercializes accessories for newborns and small kids. The company created a very detailed and interesting project work based principally on the module of "Customer Centered Design". They are going to directly involve some of their fondest customers (mums and dads) as "ambassadors" in the distribution and communication of their products to other people. The idea, in fact, is that the "ambassadors" use the same language, share the same experience with new customers and can create the situation for a higher empathy. It's a kind of customer experience, where people can talk and discuss the "job" of being parents, without feeling to be forced to buy anything.

A material design innovation case is the one of Viastone, an SME from Bulgaria, which works in the field of natural stone. Thanks to their proprietary technology, they can produce very thin $(2 \mathrm{~mm})$ sheets of stones 
(e.g. marble, onyx). They presented their technology and portfolio of products during the full course in Sofia. Then, thanks to DfE, Viastone got in touch with Valcucine, a company that designs and produces kitchen in the North-East of Italy, which participated in another short course. The concept they are dealing with is about the use of the $2 \mathrm{~mm}$ stone technology as core material for a new line of the kitchen. Stone has always been an idea for Valcucine, but unfortunately, it was difficult to implement, mainly because of the weight. The enabling technology from Bulgaria can now probably overcome the barrier (Garrone, Morelli, and Pestarino 2018).

These are just a representative selection of the many success stories born after the experience of DfE project, here reported in order to give an indication of the possible applications and general potentialities of the design thinking approach as a driver for business innovation.

\section{Conclusions}

This article presented DfE, a cycle of courses designed to support designdriven innovation approach capabilities in SMEs.

The focus of the courses was to help business organizations understand the contemporary competitive challenges, but above all to learn a method and tools for implementing the design thinking in their competitive defiance. Design thinking places people (customers and users) at the center of the innovation process, in order to listen, observe and creatively interpret their needs. Starting from what is meaningful for people, design thinking pulls for real costumers value creation. At the same time, design thinking is needed for effective organizational transformation, to engage people in a widespread creative process of change, the acquisition of a different mindset, and envisioning new directions (Dell'Era, Perego, Verganti, and Zurlo, 2019).

During the courses, design-driven innovation has been presented no longer by focusing exclusively on forms aesthetic or products appeal researches, but it was mostly based to create meaningful people's experiences. The intention was to stimulate a modus operandi towards innovation that today makes the difference, compared to those who instead pull the market or push the technology without a vision on the future, and to mediate between technologies, aspirations and user's needs in designing products and services.

DfE demonstrated to SMEs that they can improve their design management skills to increase their business in various production fields: from materials to work tools; from home appliances to business services. Moreover, the consortium provided to the EEN intermediary organizations - which operate in the various European countries for business 
development - the tools to expertly mix the design-driven innovation approach with the peculiarities of the excellence of the different countries.

The project required the consortium to design master classes and a set of different activities in order to make the learning process effective during the courses. All the activities were based on the design thinking expertise of the consortium's partners. These activities have been designed and acted by the representative of the three partners, with their different approaches, mainly during the face-to-face events. The master classes, rich of case studies and teamwork activities, characterized a set of interactive and business-oriented sessions. These helped also create a friendly atmosphere, stimulating the participants in a proactive attitude and generating a participative process of learning about the fundamentals of the design thinking. The intense involvement and engagement of all participants is an effective way to let them feel confident during the learning process. Through the collaboration between different partners, participants also brought their work closer to the purpose of their life.

The inputs brought by ADIper as the Loccion Group video, the "play40" cards brainstorming activity and the business cases brought directly by ADI members' CEOs (e.g. Domenico Guzzini for Gruppo Guzzini and Mario Fedriga for Technogym) had a strong impact among the participants, in particular regarding the perception of the design thinking as a core competence to develop a responsive, creative and flexible organizational culture to succeed in the market.

Identifying the cultural barriers that are holding back innovation in the organization, it is possible to reduce enterprises' inertia and implement successfully their drive for change. It was a good start to nurture mindset and attitude of the participant enterprises and shape their organizational culture, which is the fundamental premise for any kind of innovation: products, services, processes, business models, etc. stimulating change in the mindset. Design thinking is increasingly adopted not only to innovate products and services but also with the aim of transform businesses reshaping the organizational culture, to be confident to the creative process, to believe in the possibility of an organizational transformation towards codesign and co-develop process.

During the DfE design and organization process ADI had the opportunities to open an encounter among academic partners concerning SMEs, B2B and B2C enterprises and start-ups, bringing its experience from the Italian design and design management ecosystem. Through an intense and deep analysis and interpretation work of business case histories, carried out in collaboration with the Department of Design of Politecnico di 
Milano, for ADI it was possible to derive strategies and then disclose the methods derived from these same business cases (Ferrara 2018).

Moreover, the ADIper's activity concerning the communication strategy and its intense work through social networking communication created an ecosystem made of different players operating with completely different aims and goals, although able to collaborate with their expertise toward innovation. These are intermediary organizations, small and medium consolidated enterprises, start-ups and firms providing design thinking (strategy consulting organizations, design studios, digital agencies, technology developers). The interconnections between these different players are crucial to enriching the design thinking process, delivering an innovative product or service.

Thanks the high results and interest aroused by the issues addressed, the course has given rise to several further private initiatives, requested by the individual companies and participating associations, to ensure that the contents could be further shared with other employees or associated companies and increase the impact and efficiency of the Design for Enterprises project accordingly. 


\section{References}

Brown, Tim (2009), Change by Design: How Design Thinking Transforms Organizations and Inspires Innovation. HarperCollins.

Buchanan, Richard (1992), "Wicked Problems in Design Thinking", Design Issues, 8 (2), 5-21. https://doi.org/10.2307/1511637

Capaldo, Antonio (2007), "Network Structure and Innovation: The Leveraging of a Dual Network as a Distinctive Relational Capability", Strategic Management Journal, 28 (6), 585-608. https://doi.org/10.1002/smi.621

Chan Kim, W. and Renee Mauborgne (2005), Blue Ocean Strategy. Harvard Business Review Press.

Cross, Nigel (2011), Design Thinking: Understanding How Designers Think and Work. Oxford: Berg.

Dell'Era Claudio and Roberto Verganti (2007), "Strategies of Innovation and Imitation of Product Languages", Journal of Product Innovation Management, 24, 580-99. https://doi.org/10.1111/j.15405885.2007.00273.x

Dell'Era, Claudio, Alessandro Perego, Roberto Verganti, Roberto. and Francesco Zurlo (2019), "Mapping design thinking: transformations, Applications and Evolutions," Politecnico di Milano, School of Management, Observatory Design Thinking for Business.

Design for Enterprises (2017a), "Loccioni - Who we are, who we were", Youtube, (accessed on January 16, 2019), [available at: https://www.youtube.com/watch?v=uDIXyR-oJZw].

(2017b), "Loccioni - Play Factory", Youtube, (accessed on January 16, 2019), [available at: https://www.youtube.com/watch?v=4Bk9rFyxxMg].

EU (2013), Design for Innovation, Europa, (accessed on: January 16, 2019), [available at: https://ec.europa.eu/growth/industry/innovation/policy/design en].

------ (2015), User Guide to the SME Definition EU, Europa, (accessed on April 5, 2019), [available at: https://ec.europa.eu/docsroom/documents/15582/attachments/1/tra nslations].

Ferrara, Marinella (2018), "Un Metodo per l'Europa”, ADIDESIGN, 2 (6), (accessed on April 2, 2019), [available at: http://adidesign.org/upl/AAA\%20ADIDESIGN/ADIDESIGN\%201802\%20IT\% 20bd.pdf].

Garrone, Maddalena, Morelli, Valentina, and Pestarino, Andrea (2018), "Capabilities for Design-Driven Innovation", project final report, Doc. No. P0000447-1-H2 EASME Bruxelles, Belgium. 
Hosoe, Isao (2008) "Il Gioco", Youtube, (accessed on Jannuary 16, 2019), [available https://www.youtube.com/watch?time continue $=109 \& v=L u$ X8m9vt $5 \mathrm{w}]$.

Kolko, Jon (2015), "Design Thinking comes of Age", Harvard Business Review, 93 (9), 66-71.

Liedtka, Jeanne (2015), "Perspective: Linking Design Thinking with Innovation Outcomes through Cognitive Bias Reduction", Journal of Product Innovation Management, 32 (6), 925-38. https://doi.org/10.1111/jpim.12163

Lockwood, Thomas (2010), Design Thinking. Integrating Innovation, Customer Experience, and Brand Value. Design Management Institute. New York: Allworth Press.

Macdonald, Stuart (2004), Design Issue in Europe Today, Barcelona: The Bureau of European Design Associations - BEDA.

Martin, Roger L. (2009), The Design of Business: why Design Thinking is the next Competitive Advantage, Boston: Harvard Business Press.

Pestarino, Andrea (2018), "Una Rete Informativa”, ADIDESIGN, 2 (6), (accessed on April 2, 2019), [available at: http://adidesign.org/upl/AAA\%20ADIDESIGN/ADIDESIGN\%201802\%20IT\% 20bd.pdf].

Teal, Randall (2010), "Developing a (non-linear) Practice of Design Thinking", The International Journal of Art \& Design Education, 29 (3), 294-302. https://doi.org/10.1111/j.1476-8070.2010.01663.x

Verganti, Roberto (2009), Design-driven Innovation. Changing the Rules of Competition by Radically Innovating What Things Mean, Harvard: Harvard Business School Press.

Verganti, Roberto and Claudio Dell'Era (2014), "Design-Driven Innovation: Meaning as a Source of Innovation", in The Oxford Handbook of Innovation Management, M. Dodgson, D. Gann and N. Philips (eds.), Oxford: University Press, 139-62. 